\title{
Growth hormone replacement in patients with Langerhan's cell histiocytosis
}

\author{
S J Howell, P Wilton, S M Shalet
}

\begin{abstract}
Objectives-To assess the impact of growth hormone on growth and the underlying disease in children with growth hormone deficiency as a result of Langerhan's cell histiocytosis.

Study design-Retrospective analysis of data from the Kabi (Pharmacia \& Upjohn) international growth database (KIGS) for 82 children with Langerhan's cell histiocytosis treated with recombinant growth hormone.

Results-At the start of treatment the median (10-90th centile) age was 9.0 (5.2 to 14.7) years, with a median height standard deviation score (SDS) of -2.0 ( -3.5 to -0.9). The median pretreatment height velocity (measured in $\mathrm{cm} /$ year) was 3.6 (0.9 to 6.4); this increased to 8.8 (3.8 to 12.0) in the first year of treatment with growth hormone, and then remained significantly greater than the pretreatment height velocity at 7.3 (4.4 to 9.7$)$ and $7.1(4.1$ to 9.3$) \mathrm{cm} /$ year in the second and third years, respectively. The median height SDS increased from -2.0 to -0.8 $(-2.3$ to 0.6$)$ by the end of three years of treatment. There was no increase in the recurrence rate of the underlying disease and no adverse event could be directly attributed to growth hormone treatment, apart from one case of benign intracranial hypertension that resolved on stopping treatment with growth hormone.

Conclusions-Growth hormone replacement treatment for patients with Langerhan's cell histiocytosis with growth hormone deficiency is beneficial and safe. (Arch Dis Child 1998;78:469-473)
\end{abstract}

Keywords: growth hormone replacement; Langerhan's cell histiocytosis; pituitary gland

Department of

Endocrinology,

Christie Hospital NHS

Trust, Withington,

Manchester M20 4BX,

UK

S J Howell

S M Shalet

KIGS/KIMS,

Pharmacia \& Upjohn, Stockholm, Sweden (on behalf of the

International Board of KIGS)

P Wilton

Correspondence to:

Professor Shalet.

Accepted 3 February 1998 region demonstrable by computed tomography. ${ }^{6}$ Anterior pituitary dysfunction is less common and has been described in $1-5 \%$ of patients, ${ }^{45}$ with growth hormone deficiency being almost invariably present in these patients.

The response to growth hormone in children with Langerhan's cell histiocytosis and growth hormone deficiency was first reported by Braunstein et al in $1975^{8}$ when they described five children who had a significant improvement in height velocity during two years of treatment with growth hormone. There are only two other reports about the treatment of growth hormone deficiency due to Langerhan's cell histiocytosis, ${ }^{9}{ }^{10}$ each describing one patient whose growth rate improved with growth hormone replacement. No large cohort of patients with Langerhan's cell histiocytosis treated with growth hormone replacement has previously been reported. Examination of the effects of growth hormone treatment in patients with Langerhan's cell histiocytosis is important to ensure that it is safe and effective.

We reviewed 82 patients with growth hormone deficiency and Langerhan's cell histiocytosis who were enrolled in the Kabi (Pharmacia \& Upjohn) international growth database (KIGS) between 1988 and 1995. All were treated with recombinant growth hormone. We calculated the growth rates of patients before and for the first three years after starting treatment with growth hormone and compared these with the growth response of children with growth hormone deficiency from other causes. We also recorded the incidence of adverse events.

\section{Patients and methods}

The data were collected retrospectively from the KIGS database that was set up in 1987 to monitor the progress of children treated with recombinant growth hormone (Somatonorm or Genotropin; Pharmacia \& Upjohn, Stockholm, Sweden). Cross sectional data were available for 82 patients with Langerhan's cell histiocytosis at the start of treatment, 61 after one year of treatment, 40 after two years, and 30 after three years. Age, height (in $\mathrm{cm}$ ), and height standard deviation score (SDS) (calculated using the Tanner standards) were recorded for all patients. Height velocity, measured in $\mathrm{cm} /$ year, was calculated for 47 of the 82 patients before treatment and in all patients after the start of treatment with growth hormone. The target height was estimated in boys as 0.5 (mother's height + father's height +13 ) and in girls as 0.5 (mother's height + father's height -13 ). The actual height SDS minus the target height SDS was calculated for most patients (76 pretreatment, 56 at one year, 36 at two years, and 26 at three 


\section{Table 1 Baseline characteristics}

Number (\%) male

Number $(\%)$ female

Median (10th, 90th centile) age at diagnosis of LCH (years) $(\mathrm{n}=50)$

Median (10th, 90th centile) age at start of GH (years) $(n=82)$

Median (10th, 90th centile) height SDS ( $\mathrm{n}=82$ )

Median (10th, 90th centile) height - target height SDS $(n=76)$

Height velocity in $\mathrm{cm} /$ year $(\mathrm{n}=47)$

Number $(\%)$ TSH deficient $(\mathrm{n}=79)$

Number $(\%)$ ACTH deficient $(\mathrm{n}=78)$

Number $(\%)$ LH, FSH deficient $(\mathrm{n}=57)$

Number $(\%)$ with diabetes insipidus $(\mathrm{n}=79)$

$\mathrm{n}$, number of patients for whom information was available.

LCH, Langerhan's cell histiocytosis; GH, growth hormone treatment; TSH, thyroid stimulating hormone; ACTH, adrenocorticotrophin hormone; $\mathrm{LH}$, luteinising hormone; $\mathrm{FSH}$, follicle stimulating hormone.

years). Other anterior and posterior pituitary hormone deficits were recorded in 79 of the 82 patients at baseline.

Details of previous treatment for Langerhan's cell histiocytosis were recorded for most patients. Twenty of 78 patients received cranial irradiation. The dose of irradiation was relatively small in most patients (16 Gy or less in 10 of 11 patients in whom this information was available), and in only seven was the hypothalamic pituitary region definitely within the field of irradiation. All but two of the irradiated patients had diabetes insipidus (but in no individual was radiotherapy given specifically to treat this complication). Forty four of 69 patients were treated with cytotoxic chemotherapy, whereas 31 of 46 received steroids. The pubertal status of patients was recorded in most patients at all visits (60 pretreatment, 46 at one year, 34 at two years, and 27 at three years). Entry into puberty was defined as breast stage 2 for girls and a testicular volume of $4 \mathrm{ml}$ for boys.

A proportion of the children had entered puberty by the end of the three years of study. Therefore, longitudinal data from a subset of 17 children who remained prepubertal throughout were analysed separately. Height SDS and height velocity were recorded in all patients at all times, except for six patients whose height velocity was not calculated before treatment. The target height was estimated in all but two subjects and therefore the height SDS minus the target height SDS was calculated for 15 patients at zero, one, two, and three years.

\section{Results}

The diagnosis of growth hormone deficiency was based on auxological criteria (height SDS,

Table 2 Median (10th, 90th centile) height SDS, height - target height SDS, and height velocity (cm/year) before and during growht hormone replacement treatment

\begin{tabular}{llll}
\hline & Height SDS & $\begin{array}{l}\text { Height - target height } \\
\text { SDS }\end{array}$ & $\begin{array}{l}\text { Height velocity } \\
\text { (cm/year) }\end{array}$ \\
\hline $\begin{array}{l}\text { Cross sectional } \\
\text { Pretreatment }(\mathrm{n}=82)\end{array}$ & $-2.0(-3.5,-0.9)$ & $-1.8(-3.0,-0.5)^{\star}$ & $3.6(0.9,6.4) \dagger$ \\
1 year $(\mathrm{n}=61)$ & $-1.8(-3.2,-0.1)$ & $-1.4(-2.6,-0.1)$ & $8.8(3.8,12.0)$ \\
2 years $(\mathrm{n}=40)$ & $-1.5(-3.0,0.1)$ & $-1.3(-2.6,0.2)$ & $7.3(4.4,9.7)$ \\
3 years $(\mathrm{n}=30)$ & $-0.8(-2.6,0.4)$ & $-1.1(-2.3,0.6)$ & $7.1(4.1,9.3)$ \\
Longitudinal $(n=17)$ & $-2.0(-4.1,-1.1)$ & $-2.4(-3.9,-1.0) \ddagger$ & $4.5(0.9,6.5) \subseteq$ \\
Pretreatment & $-1.6(-3.2,-0.4)$ & $-2.1(-3.3,-0.4) \ddagger$ & $8.9(5.6,13.1)$ \\
1 year & $-1.1(-2.5,0.2)$ & $-1.7(-2.6,0.1) \ddagger$ & $7.3(3.7,9.9)$ \\
2 years & $-0.8(-2.6,0.5)$ & $-1.5(-2.5,0.6) \ddagger$ & $7.3(4.2,9.3)$ \\
\hline
\end{tabular}

^Data from 76 patients; †data from 47 patients; $\ddagger$ data from 15 patients; \data from 11 patients. height velocity) along with the growth hormone response to standard stimulation tests, insulin induced hypoglycaemia and arginine being the most commonly used agents. The median (10-90th centile) growth hormone peak during provocative testing was $2.1 \mu \mathrm{g} / 1$ (0.4-5.0) (conversion to IU: $1 \mu \mathrm{g} / 1=3 \mathrm{mU} / \mathrm{l}$ ) in the group as a whole and $2.0 \mu \mathrm{g} / 1(0.2-5.3)$ in the 17 prepubertal patients followed longitudinally. All patients were subsequently treated with growth hormone at a median dose of $0.17 \mathrm{mg} / \mathrm{kg} /$ week $(0.14-0.26)$.

Table 1 shows the baseline characteristics of the 82 children. The male to female ratio of $2: 1$ is similar to the observed sex ratio of patients with Langerhan's cell histiocytosis. ${ }^{45} 7$ The median height velocity in $\mathrm{cm} /$ year and height SDS are both reduced, in keeping with a diagnosis of growth hormone deficiency. Diabetes insipidus was present in $67 \%$ of patients, whereas other pituitary hormone deficiencies occurred less often. All patients were receiving adequate replacement treatment for other hormone deficiencies before starting growth hormone treatment.

Pubertal status was recorded in 60 of the 82 patients at baseline and eight children had entered puberty. Eleven of 46, nine of 34, and 10 of 27 children had entered puberty by one, two, and three years, respectively. The corresponding median chronological ages of these groups was $9.0,9.8,10.3$, and 11.0 years.

Table 2 gives the response to growth hormone replacement, showing the height SDS and height velocity before and during the first, second, and third years of treatment. The height velocity is greatest in the first year of treatment and remains well above baseline for the second and third years. The height SDS and height minus target height SDS both steadily improve throughout the whole three years, with a median height SDS after three years of treatment of -0.8 .

Growth was followed longitudinally in 17 patients. Their median age at diagnosis of Langerhan's cell histiocytosis was 2.2 years, whereas the median age at the start of growth hormone treatment was 7.3 years. One patient was deficient in adrenocorticotrophic hormone, thyroid stimulating hormone, and gonadotrophin, and nine patients had diabetes insipidus. Table 2 also gives the height and height velocity before and during treatment for this group. Similar results to the larger dataset from the total cohort can be seen, with a significantly increased height velocity in the first year, which is maintained well above the baseline during the subsequent two years. The height SDS also increases throughout the three years of treatment, reaching a median value of -0.8 at the end of the third year.

Analysis of the patients according to their exposure to cranial irradiation or chemotherapy showed no significant difference in baseline growth parameters between those who had received radiotherapy or drug treatment and those who had not.

The response to growth hormone treatment has been reported in other patients with organic or idiopathic growth hormone 
Table 3 Height velocity (cm/year) in patients with idiopathic growth hormone deficiency and growth hormone deficiency associated with Langerhan's cell histiocytosis

\begin{tabular}{llll}
\hline & & \multicolumn{2}{l}{ Langerhan's cell histiocytosis } \\
\cline { 3 - 4 } & Idiopathic $(n=289)$ & Cross sectional $(n=82)$ & Longitudinal $(n=17)$ \\
\hline Pretreatment & N/A & $3.6(0.9,6.4)^{\star}$ & $4.5(0.9,6.5) \dagger$ \\
1st year of treatment & $8.8(5.8,12.9)$ & $8.8(3.8,12.0)$ & $8.9(5.6,13.1)$ \\
2nd year of treatment & $6.7(4.7,9.4)$ & $7.3(4.4,9.7)$ & $7.3(3.7,9.9)$ \\
\hline
\end{tabular}

Values are median (10th, 90th centiles).

$\star$ Data from 47 patients; †data from 11 patients.

deficiency. ${ }^{11-13}$ Ranke and Guilbaud ${ }^{11}$ published data on a group of 289 prepubertal children with idiopathic growth hormone deficiency. All had growth hormone concentrations of $<20 \mathrm{mU} / 1$ on standard stimulatory testing and had been entered into KIGS. Table 3 compares the response to treatment with growth hormone between the 289 patients with idiopathic growth hormone deficiency and the 82 with Langerhan's cell histiocytosis in this study. The height velocity during the first year is almost identical in the two groups and there is little difference in the second year growth responses.

ADVERSE EVENTS

One patient developed benign intracranial hypertension 15 days after starting treatment with growth hormone at a dosage of $0.19 \mathrm{mg} /$ $\mathrm{kg} /$ week. Computed tomography at this time was normal and the disorder resolved when treatment with growth hormone was stopped; this was later restarted at a lower dose and subsequently increased up to the original dose without any recurrence. Six months after presenting with benign intracranial hypertension the patient developed headaches and visual field loss. Computed tomography showed a new $2 \times 2 \mathrm{~cm}$ mass in the pituitary region, which a biopsy sample proved to be a germinoma.

One patient had pre-existing ataxia that worsened during growth hormone treatment. Treatment was subsequently stopped in this patient. Two children developed central hypothyroidism. These two patients had at least two other pituitary hormone deficits (growth hormone and antidiuretic hormone in one patient, and growth hormone, antidiuretic hormone, and gonadotrophin in the other). Three patients had a recurrence of Langerhan's cell histiocytosis. One had a lesion that was sited in the mandible, one had a suprasellar lesion which responded well to chemotherapy, whereas in the third the site was not recorded. Two patients sustained a fracture of the radius, but no information about an underlying bone lesion is available. Hypercholesterolaemia occurred in two patients, nausea in one, eczema in one, and one patient underwent a tonsillectomy.

\section{Discussion}

We have described a large group of patients deficient in growth hormone with Langerhan's cell histiocytosis who were treated with growth hormone. Both cross sectional and longitudinal data show a poor median height velocity pretreatment, which markedly improved after treatment with growth hormone. This im- proved rate of growth was maintained for at least three years and resulted in an increase in height SDS.

There are potential problems in using data obtained from an international database such as KIGS. The reliability of such data is dependent on accurate diagnosis and reporting by many different investigators. The diagnosis of Langerhan's cell histiocytosis, however, was not revised in any of the study patients during a mean follow up of over five years. There was also documented evidence of growth hormone deficiency in all patients and diabetes insipidus in two thirds of the patients. A large proportion of the 20 children who received cranial irradiation received radiotherapy to a skull Langerhan's cell histiocytosis lesion with a dose sufficiently low to exclude the possibility of radiation induced growth hormone deficiency. Furthermore, all but two of the 20 cranially irradiated children had diabetes insipidus, a complication that has never been documented after irradiation. Growth hormone deficiency and diabetes insipidus are recognised complications of Langerhan's cell histiocytosis and these hormone deficiencies could not be attributed to their treatment or to any other cause during prolonged follow up. It therefore seems reasonable to conclude that the diagnosis of Langerhan's cell histiocytosis was correct in most patients and that the cause of their growth hormone deficiency was the disease itself.

The safety data are similarly dependent on the accurate reporting of the side effects of treatment. However, although trivial side effects may not be fully documented, it is extremely unlikely that any significant adverse events would not be reported. It is the occurrence of serious side effects and, in particular, the recurrence or progression of Langerhan's cell histiocytosis, that is of greatest importance in these children, and it is likely that in this respect our data are accurate. Thus although there are fundamental problems inherent in analysing data from any large international database, it is unlikely that any errors in data collection would significantly alter our conclusions. The safety data are critically important for the clinician and there is no realistic possibility that such information could ever be collected from a single centre. Thus only a large international database, with all its inherent limitations, can truly address this issue.

The rate of growth in response to growth hormone replacement in patients with Langerhan's cell histiocytosis is similar to that observed in children with idiopathic growth hormone deficiency. ${ }^{11}$ Direct comparison of the results of all 82 children is difficult because of the differences in patient characteristics. Twenty six per cent of the patients with Langerhan's cell histiocytosis had entered puberty by the end of the second year, compared with only nine $(3 \%)$ of the idiopathic group. Puberty, however, is not the only factor that influences the initial response to growth hormone. Ranke and Guilbaud ${ }^{11}$ found that the first year height velocity was negatively corre- 
Table 4 Factors that influence first year height velocity in patients with idiopathic growth hormone deficiency and growth hormone deficiency associated with Langerhan's cell histiocytosis

\begin{tabular}{llll}
\hline & & \multicolumn{2}{l}{ Langerhan's cell histiocytosis } \\
\cline { 3 - 4 } & $\begin{array}{l}\text { Idiopathic } \\
(n=289)\end{array}$ & $\begin{array}{l}\text { Cross sectional } \\
(n=82)\end{array}$ & $\begin{array}{l}\text { Longitudinal } \\
(n=17)\end{array}$ \\
\hline Age (years) & 7.0 & 9.0 & 7.3 \\
DHT & 2.4 & $1.8^{\star}$ & $2.4 \dagger$ \\
Growth hormone dose (mg/kg/week) & 0.2 & 0.17 & 0.19 \\
Injection frequency & $5 /$ week & $6 /$ week & $6 /$ week \\
Pubertal & None & $13.3-23.9 \%$ & None \\
\hline
\end{tabular}

Age and DHT values are for the start of the first year. Growth hormone dose and injection frequency are median values based on the whole of the first year. The range quoted for puberty in the cross sectional patients is the percentage who had entered puberty at the start and end of the first year.

${ }^{\star}$ Data from 76 patients; $\dagger$ data from 15 patients.

DHT, target height SDS - height SDS.

lated with age and height SDS and positively correlated with growth hormone dose, frequency of injection, and target height SDS. Height SDS and target height SDS can be combined into one variable, target height minus height SDS (DHT), which is positively correlated with the first year height velocity. Table 4 shows a comparison of the factors that influence the observed response to growth hormone in the first year in our group of children with Langerhan's cell histiocytosis and the idiopathic growth hormone deficiency group. The 82 children with Langerhan's cell histiocytosis were older and had a lower median DHT than the patients with idiopathic growth hormone deficiency. Thus when comparing the two groups, any growth advantage conferred on the patients with Langerhan's cell histiocytosis by the higher incidence of puberty is likely to be offset by their greater chronological age and lower DHT at the start of treatment. It is therefore likely that any bias introduced by the different baseline characteristics is not great. This is confirmed when the subset of 17 prepubertal children are compared with the idiopathic growth hormone deficiency group. The influential factors were almost identical, whereas the growth response to growth hormone was at least as good in the patients with Langerhan's cell histiocytosis as in the idiopathic growth hormone deficiency group.

The data for patients with Langerhan's cell histiocytosis also compare favourably with those obtained in children with organic growth hormone deficiency. Cross sectional data from 723 children with central nervous system tumours $^{12}$ and 103 children treated for acute lymphoblastic leukaemia ${ }^{13}$ have previously been analysed from the KIGS database. The median pretreatment height velocity in these groups was similar to that in the Langerhan's cell histiocytosis cohort. First, second, and third year height velocities, however, were lower than those observed in the Langerhan's cell histiocytosis cohort, suggesting there may be a better growth response to growth hormone replacement in patients with Langerhan's cell histiocytosis than in those irradiated for acute lymphoblastic leukaemia or central nervous system malignancy.

Adverse events that could be attributed to growth hormone were minimal. Spontaneous recurrence of Langerhan's cell histiocytosis has previously been reported at varying frequencies and times after initial diagnosis. Gadner and colleagues $^{14}$ found a recurrence rate of $12-42 \%$ during a median follow up of almost seven years. Kilpatrick and colleagues ${ }^{7}$ studied 263 paediatric and adult cases of Langerhan's cell histiocytosis over a mean time of 12 years and found a recurrence rate of $17 \%$, but a much higher frequency $(48 \%)$ in patients with diabetes insipidus. Therefore, considering the high incidence of diabetes insipidus in our cohort, a definite recurrence of the disease in only three, and at the most five, of the 82 patients during a three year period does not represent an excessively high recurrence rate.

One patient developed a central nervous system malignancy preceded by intracranial hypertension. It is possible that the symptoms and signs on which the diagnosis of benign intracranial hypertension was based were in fact due to the developing tumour, although the absence of abnormalities on the scan and the clinical response to stopping growth hormone would argue against this. Benign intracranial hypertension is a recognised side effect of growth hormone replacement, which usually improves on stopping treatment. ${ }^{15}$ Central nervous system malignancies, however, have not been shown to occur with increased frequency in patients receiving growth hormone. ${ }^{16}{ }^{17}$ None of the other adverse events has previously been associated with growth hormone replacement and it seems unlikely that their occurrence was related to the treatment. Thus the use of growth hormone in this group of patients with growth hormone deficiency does not appear to be associated with any unwanted side effects other than the one case of benign intracranial hypertension, which resolved on stopping treatment with growth hormone.

Thus we have shown that the growth response to growth hormone replacement in children with Langerhan's cell histiocytosis is at least as good as that seen in other patients with growth hormone deficiency. No increase has been shown in the activity of the underlying disease while receiving growth hormone, and no excess of other adverse events attributable to growth hormone treatment. We can therefore conclude, based on the data obtained from a substantial cohort of patients, that growth hormone treatment of patients with Langerhan's cell histiocytosis and growth hormone deficiency is beneficial, in terms of improved growth rate, and is also safe.

Declaration of interest: Some of Professor Shalet's clinical research activities are supported financially by pharmaceutical companies producing growth hormone.

1 Willman CL, Busque L, Griffith BB, et al. Langerhans' cell histiocytosis (histiocytosis $\mathrm{X}$ ) - a clonal proliferative disease. N Engl f Med 1994;331:154-60.

2 Dunger DB, Broadbent V, Yeoman E, et al. The frequency and natural history of diabetes insipidus in children with Langerhans cell histiocytosis. $N$ Engl f Med 1989;321: 1157-62.

3 Sims DG. Histiocytosis X; follow-up of 43 cases. Arch Dis Child 1977;52:433-40.

4 Grois N, Flucher-Wolfram B, Heitger A, Mostbeck GH, Hofmann J, Gadner H. Diabetes insipidus in Langerhans
cell histiocytosis: results from the DAL-HX 83 study. Med Pediatr Oncol 1995;24:248-56. 
5 The French Langerhan's Cell Histiocytosis Study Group. A multicentre retrospective survey of Langerhan's cell Arch Dis Child 1996;75;17-24.

6 Broadbent V, Dunger DB, Yeomans E, Kendall B. Anterior pituitary function and computed tomography/magnetic resonance imaging in patients with Langerhans cell histiocytosis and diabetes insipidus. Med Pediatr Oncol 1993;21: 649-54.

7 Kilpatrick SE, Wenger DE, Gilchrist GS, Shives TC, Wollan PC, Unni KK. Langerhan's cell histiocytosis (histiocytosis $\mathrm{X}$ ) of bone. A clinicopathologic analysis of 263 paediatric and adult cases. Cancer 1995;76:2471-84

8 Braunstein GD, Raiti S, Hansen JW, Kohler PO. Response of growth-retarded patients with Hand-Schuller-Christian disease to growth hormone therapy. $N$ Engl $f \mathrm{Med}$ 1975;292:332-3.

9 Dean HJ, Bishop A, Winter JS. Growth hormone deficiency in patients with histiocytosis X. F Pediatr 1986;109:615-18.

10 Van den Hoek AC, Karstens A, Egeler RM, Hahlen K. Growth of children with Langerhans cell histiocytosis. Eur Growth of children with

11 Ranke MB, Guilbaud O. Growth response in prepubertal children with idiopathic growth hormone deficiency during the first two years of treatment with human growth hormone. Analysis of the Kabi Pharmacia internationa growth study. Acta Paediatr Scand Suppl 1991;379:109-16.
12 Clayton PE, Shalet SM, Price DA. Growth hormone treatment in children with CNS malignancy. In: Ranke MB, Gunnarsson R, eds. Progress in growth hormone therapy-5 years of KIGS. Mannheim: J and J Verlag, 1994:157-89.

3 Price OA, Clayton PE. Growth hormone treatment in children in remission from leukaemia. In: Ranke $M B$, Gunnarsson R, eds. Progress in growth hormone therapyyears of KIGS. Mannheim: J and J Verlag, 1994:157-89.

14 Gadner H, Heitger A, Grois N, Gatterer-Menz I, Ladisch S. Treatment strategy for disseminated Langerhans cell Treatment strategy for disseminated Langerhans cell
histiocytosis. DAL HX-83 study group. Med Pediatr Oncol 1994;23:72-80.

15 Malozowski S, Tanner LA, Wysowski DK, Fleming GA, Stadel BV. Benign intracranial hypertension in children with growth hormone deficiency treated with growth hormone. F Pediatr 1995;126:996-9.

16 Blethen SL, Allen DB, Graves D, August G, Moshang T, Rosenfeld R, on behalf of the national cooperative. Safety of recombinant deoxyribonucleic acid-derived growth hormone: the national cooperative growth study experience. F Clin Endocrinol Metab 1996;81:1704-10.

17 Wilton P. Adverse events during growth hormone treatment: 5 years experience in the Kabi International growth study. In: Ranke MB, Gunnarsson R, eds. Progress in growth hormone therapy -5 years of KIGS. Mannheim: J and J, 1994:291-307. 